\title{
Mechanical models and support technologies for retaining gob-side entry Yunliang TAN ${ }^{1,2}$, Yanchun YIN ${ }^{1,2}$, Jianguo NING ${ }^{1,2}$, Tongbin ZHAO $^{1,2}$
}

\author{
(1. State Key Laboratory Breeding Base for Mining Disaster Prevention and \\ Control, Shandong University of Science and Technology, Qingdao, Shandong \\ 266590, China; 2. College of Mining and Safety Engineering, Shandong University \\ of Science and Technology, Qingdao, Shandong 266590, China)
}

\begin{abstract}
Aiming at gob-side entry retaining for three typical roof conditions (hard roof, medium stable roof and limestone roof), theoretical analysis, numerical simulation, laboratory test and field test were carried out. Different support mechanical models were built, and various roadside support technologies were presented. Results show that: for retaining gob-side entry of hard roof, flexible-stiff support mechanical model was built, quantitative calculation method of thickness, strength and size of flexible and stiff filling body were deduced, and filling materials of flexible and stiff support body were developed. Strain hardening characteristic of anchored gangue body was revealed, and roadside filling support technology with transversely anchored gangue body was presented for retaining gob-side entry of medium stable roof. Based on the slow subsidence motion characteristic of limestone roof, cutting off roof of roadside support with hydraulic props, anchor cables and auxiliary blasting was proposed, and showed good cutting effect.
\end{abstract}

Keywords: retaining gob-side entry; hard rocks; medium stable roof; limestone roof.

\section{Introduction}

In most mining roadways, there leaves an amount of entry protection coal pillars, which is a waste of coal, and more tendency to rock burst [1-3]. The technology of retaining gob-side entry can increase coal recovery rate and mine economic effect, control rock burst, prevent coal and gas outburst. It has great significance in sustainable development and green mining for the coal industry [4-6]. In the past few years, many works have been done on the retaining gob-side entry for gently inclined thin and medium-thick coal seam with stable roof [7-10], but the effect of field mining production is poor. There are two main reasons: (1) roof fracture motion characteristic of different roof conditions and the influence on deformation and damage of roadway surrounding rocks have not been considered; (2) roadside support technology of retaining gob-side entry is not designed according to different roof motion characteristics. In this paper, retaining gob-side entry technologies of three typical roof conditions which are hard roof, medium stable roof and limestone roof, were researched using theoretical analysis, numerical simulation, laboratory test and field test were carried out. Different support mechanical models were built, and various roadside support technologies were presented. The research achievements have great guiding significance on the popularization and application of retaining gob-side entry.

\section{Flexible-stiff support for hard roof}

\subsection{Mechanical model}

For hard roof, like tight sandstone, there 
are two stages in the process of main roof rock beam bending and compacting gangues in the gob after face mining, as shown in Fig. 1.

Step 1: main roof rock beam bends and contacts gangues. With the bending down of the main roof rock beam, the flexible filling material is compacted gradually, which can make the roof subside slowly and prevent rock burst. The thickness of flexible materials can be estimated by:

$$
\begin{aligned}
& h_{1}= \frac{S_{A}}{L_{2}} L_{1}=\frac{h-\left(K_{A}-1\right) m_{Z}}{L_{2}} L_{1} \quad \text { (1) gangues and coal, and can } \\
& \sigma_{c} \geq \frac{\gamma_{Z} m_{Z}\left[\left(L_{1}+0.5 d\right)-L_{0}\right]+\gamma_{E} m_{E} L_{2}\left(L_{2}-L_{0}\right)-F_{A}\left(2 L_{2}-L_{0}\right)}{\left(2 L_{1}-L_{0}\right) d}
\end{aligned}
$$

where $h_{1}$ is thickness of flexible material; $S_{A}$ is maximum subsidence of the main roof; $K_{A}$ is coefficient of bulk increase; other variables are shown in Fig. 1.

Step 2: main roof rock beam contacts and compacts gangues. When the main roof continues to subside, strong materials of the filling body apply supporting reaction force to the roof, which can decrease subsidence of the roof. The supporting force is affected by the main roof, gangues and coal, and can be described as: where $\gamma_{Z}$ is the unit weight of the rock; variables are shown in Fig. 1 (b).

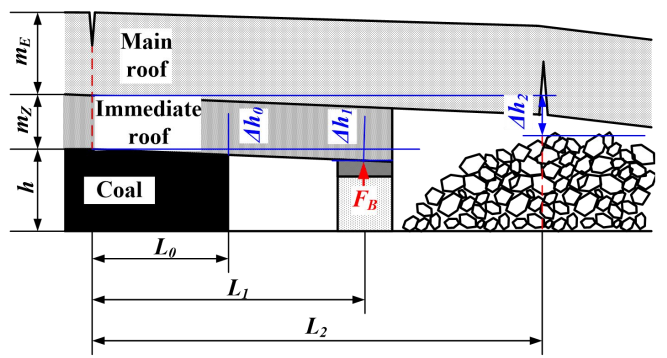

(a) Step 1

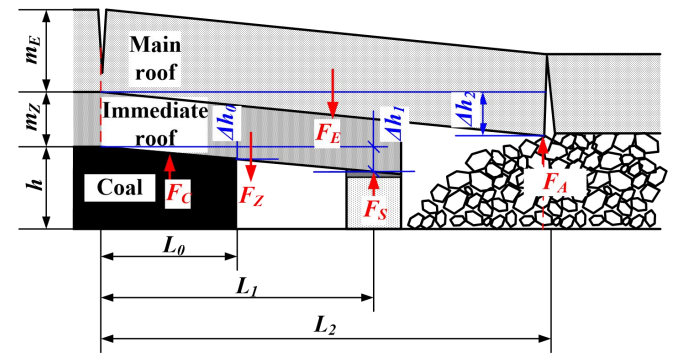

(b) Step 2

Fig. 1. Flexible-stiff support mechanical model

\subsection{Filling materials}

Raw materials of flexible material includes: foaming agent M1 and M2, foam stabilizer, fire retardant, and curing agent. Foaming agent has a great influence on the foaming effect and uniaxial compressing strength of yielding expanding polymer materials. Testing results of different kinds of foaming agent were shown in Table 1, and M2 is chosen as the foaming agent, which has bigger foaming height index.

In stiff filling materials, cement is chosen as the binding material; coal ash is active admixture with gelling property; gangue and river sand are inert materials; early strength agent and water reducing agent are modified materials. Using orthogonal experimental design method, uniaxial compressing strength and slump of stiff filling material specimens were analyzed, as shown in Table 2, and the best materials ratio was shown in Table 3 .

Table 1 Foaming effect of foaming agents

\begin{tabular}{|c|c|c|c|}
\hline \multirow{2}{*}{ Foaming agent } & $\begin{array}{c}\text { Dosage } \\
/ \mathrm{g}\end{array}$ & $\begin{array}{c}\text { Foaming height index } \\
/(\mathrm{cm} / \mathrm{g})\end{array}$ & $\begin{array}{c}\text { Compressing strength } \\
/ \mathrm{kPa}\end{array}$ \\
\hline \multirow{3}{*}{ M1 } & 25 & 0.52 & 203 \\
\cline { 2 - 4 } & 28 & 0.63 & 83 \\
\cline { 2 - 4 } & 31 & 0.72 & 124 \\
\hline \multirow{3}{*}{ M2 } & 20 & 0.56 & 243 \\
\cline { 2 - 4 } & 22 & 0.57 & 259 \\
\cline { 2 - 4 } & 24 & 0.60 & 217 \\
\hline
\end{tabular}


Table 2 Uniaxial strength and slump of strong filling materials

\begin{tabular}{|c|c|c|c|c|c|c|c|c|c|}
\hline \multicolumn{5}{|c|}{ Schemes } & \multicolumn{4}{|c|}{$\begin{array}{c}\text { Uniaxial compressing } \\
\text { strength(MPa) }\end{array}$} & \multirow{2}{*}{$\begin{array}{l}\text { Slump } \\
(\mathrm{cm})\end{array}$} \\
\hline Sequence & $\begin{array}{c}\text { Water } \\
\text { cement } \\
\text { ratio }\end{array}$ & $\begin{array}{l}\text { Coal } \\
\text { ash }\end{array}$ & $\begin{array}{c}\text { Early } \\
\text { strength } \\
\text { agent }\end{array}$ & $\begin{array}{c}\text { Water } \\
\text { reducing } \\
\text { agent }\end{array}$ & $1 d$ & $4 d$ & $7 d$ & $14 d$ & \\
\hline 1 & 0.40 & $10 \%$ & $3 \%$ & $1.5 \%$ & 2.7 & 6.933 & 10.389 & 11.784 & 22 \\
\hline 2 & 0.42 & $10 \%$ & $2 \%$ & $1 \%$ & 1.881 & 5.337 & 5.762 & 9.303 & 23 \\
\hline 3 & 0.44 & $10 \%$ & $2.5 \%$ & $2 \%$ & 1.894 & 6.13 & 9.191 & 11.542 & 12.5 \\
\hline 4 & 0.40 & $15 \%$ & $2.5 \%$ & $1 \%$ & 1.99 & 4.798 & 8.158 & 8.953 & 25 \\
\hline 5 & 0.42 & $15 \%$ & $3 \%$ & $2 \%$ & 1.737 & 4.355 & 8.296 & 11.643 & 22 \\
\hline 6 & 0.44 & $15 \%$ & $2 \%$ & $1.5 \%$ & 1.554 & 4.929 & 7.104 & 9.744 & 9 \\
\hline 7 & 0.40 & $20 \%$ & $2 \%$ & $2 \%$ & 1.635 & 4.24 & 7.205 & 8.968 & 22 \\
\hline 8 & 0.42 & $20 \%$ & $2.5 \%$ & $1.5 \%$ & 2.046 & 4.217 & 6.326 & 9.879 & 22 \\
\hline 9 & 0.44 & $20 \%$ & $3 \%$ & $1 \%$ & 1.429 & 5.334 & 8.461 & 10.538 & 19 \\
\hline
\end{tabular}

Table 3 Materials ratio of strong filling material

\begin{tabular}{|c|c|c|c|c|c|c|c|c|}
\hline \multicolumn{7}{|c|}{ Material amount (kg/t) } & Stone granularity \\
Water & Cement & Coal ash & Gangue & Sand & Stone & $\begin{array}{c}\text { Early strength } \\
\text { agent }\end{array}$ & $\begin{array}{c}\text { Water reducing } \\
\text { agent }\end{array}$ & \begin{tabular}{c} 
Sm $)$ \\
\hline 134
\end{tabular} 164 \\
\hline
\end{tabular}

\section{Transversely anchored support for medium stable roof}

\subsection{Mechanical properties of anchored filling}

Uniaxial compressing tests of common gangue body and anchored gangue body were carried out to analyze the support strength, as shown in Fig. 2.

In the test of common gangue body, support force increases slowly at the beginning, and then increases quickly, as shown in Fig. 3(a). When exceeds the support strength $6.5 \mathrm{MPa}$, support force decreases slowly. In the test of anchored gangue body, support force increases linearly approximately before ultimate strength, and decreases quickly after that, as shown in Fig. 3(b). The support strength is $13.4 \mathrm{MPa}, 2.06$ times of the strength of common gangue body, i.e., anchored gangue body shows strain hardening characteristics [11].

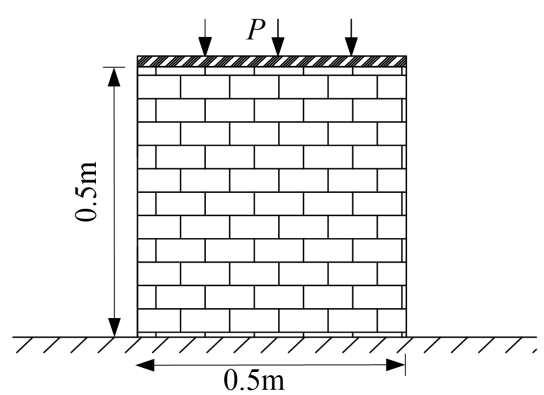

(a) Common gangue body

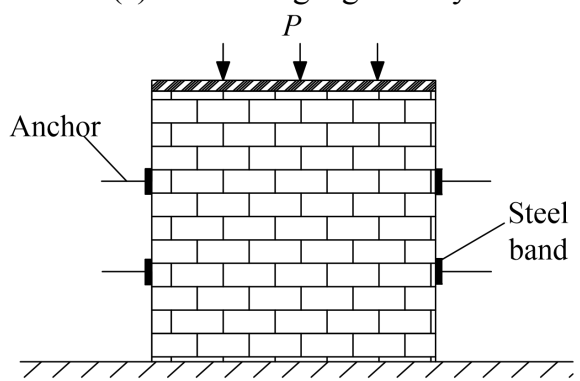

(b) Anchored gangue body

Fig. 2. Uniaxial tests of gangue body 


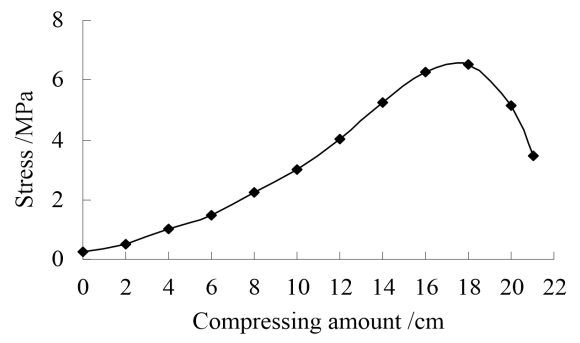

(a) Common gangue body

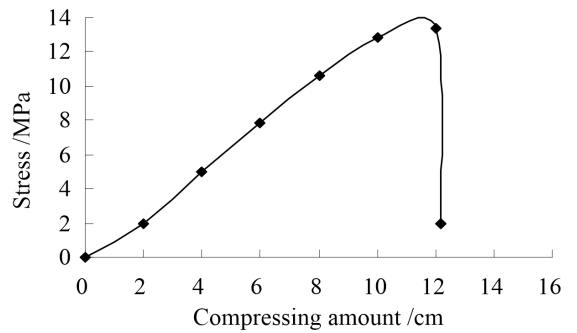

(b) Anchored gangue body

Fig. 3. Support force of the gangue body

\subsection{Support mechanical model}

For medium stable roof, the hanging arch is short, the roof subsidence is small, and the roof fracture line is close to the coal wall. The medium stable roof can be supported by transversely anchored gangue body, and the mechanical model is shown in Fig. 4.

$$
P_{2}=\frac{m_{Z} \gamma_{Z} L_{Z}^{2}+q_{E} L_{Z}^{2}-\left(m_{Z} \gamma_{Z} L_{Z}-q_{E}\right) x_{0}-P_{1}\left(b+x_{0}\right)-\sigma_{c} c\left(2 b+c+x_{0}\right)}{2 b+x_{0}}
$$

where $L_{Z}$ is the length of the immediate roof fracture rock; $P_{1}$ is the support force of the roadside filling body; $\sigma_{c}$ is the compressing strength of roadside filling body; other variables are shown in Fig. 4.

\section{Cutting off roof support for limestone roof}

\subsection{Mechanical model}

The key problem in retaining gob-side entry for limestone roof is cutting roof. Limestone roof is compressed by the upper main roof, and supported by coal, entry and roadside support. Roadside cutting off roof mechanical model for limestone roof was shown in Fig. 5.

To cut limestone roof at roadside, under the supporting reaction force and roof loading force, stress at the cutting line

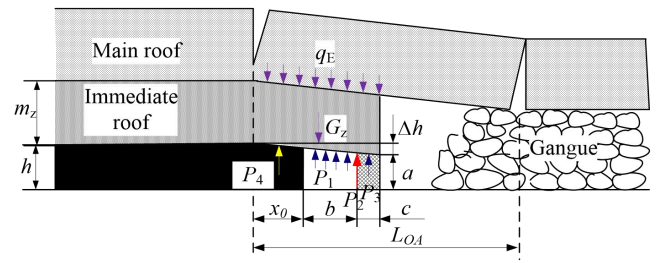

Fig. 4. Roadside support mechanical model for medium stable roof

Overburden main roof can be supported by gangue in gob and the coal, so roadside support structure only support the subsidence and deformation of the main roof. Roadside support is designed by given deformation, and the support strength is described as:

$$
\sigma=\frac{E_{a}\left(b+x_{0}\right)\left[h-m_{Z}\left(K_{A}-1\right)\right]}{a L_{O A}}
$$

where $E_{a}$ is the elastic modulus of the roadside filling body.

\subsection{Support approaches}

If the practical support capacity is smaller than the required support strength, auxiliary support should be designed, as shown in Fig. 4. Based on the equilibrium condition and compressing characteristics of gangue and support body, auxiliary support resistance can be estimated by

should exceed the ultimate tensile strength, and the cutting force can be estimated by:

$$
P_{c}=\frac{\left[\sigma_{t}\right]_{z}^{\prime} m_{Z}^{\prime 2}}{3 L_{S}}
$$

where $\left[\sigma_{t}\right]_{z}^{\prime}$ is the actual tensile strength; $m_{Z}^{\prime}$ is the effective bending thickness of the roof; $L_{S}$ is the roadside roof hanging length.

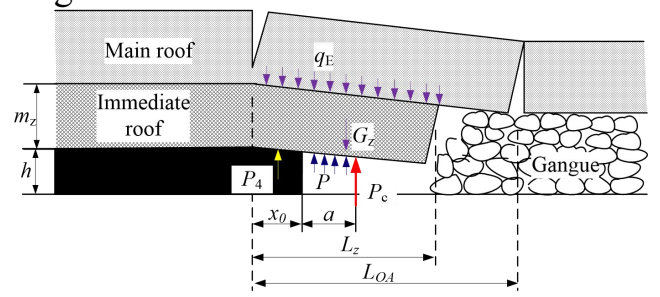

Fig. 5. Roadside roof cutting mechanical model for limestone roof 


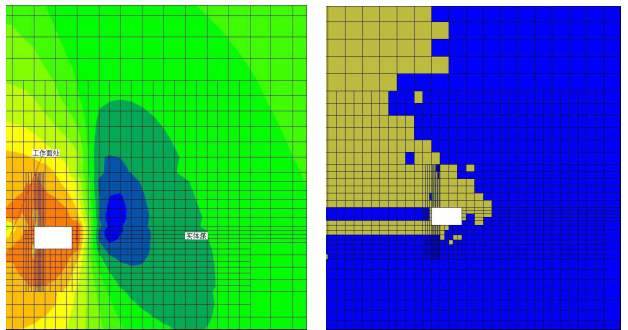

(a) Scheme 1

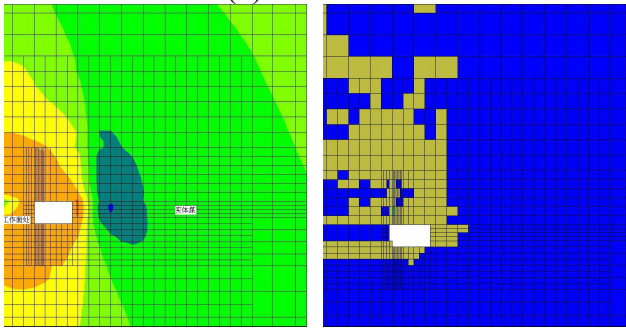

(b) Scheme 2

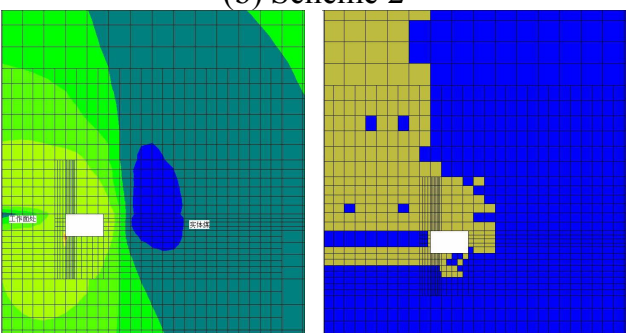

(c) Scheme 3

Fig. 6. Roof cutting effect

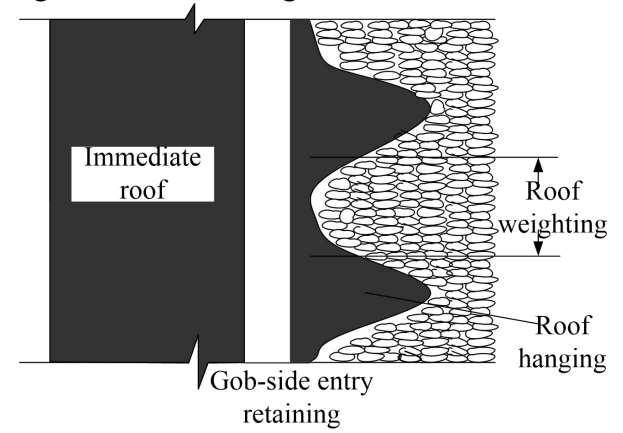

(a) Scheme 1

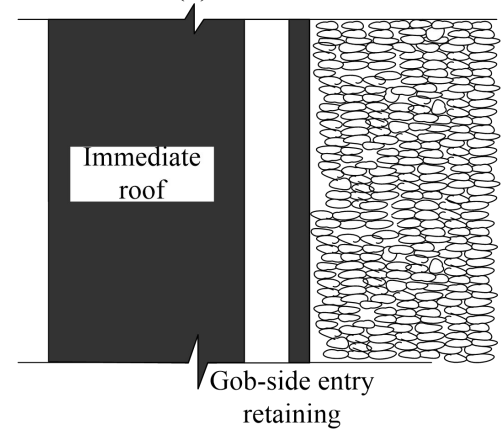

(b) Scheme 1 and auxiliary blasting

Fig. 7. Field test of roof cutting

\subsection{Cutting off roof technique}

Three schemes of roadside cutting off roof were simulated, which are cutting with anchor cables and hydraulic props (scheme 1), cutting with anchor cables and concrete buttresses (scheme 2) and cutting with intensive hydraulic props (scheme 3). Stress distribution and plastic zone in surrounding rocks of the three schemes were shown in Fig. 6. Hydraulic prop has high supporting resistance, which can restrain roof subsistence at the hanging rock seam, and promotes the initial fissure and mining cracks develop. There generates a weak plane along the cutting line where the immediate roof cut off. With high preload, anchor cables can prevent roof separation between the immediate roof and main roof, decrease the initial support force of roadside supporting body, and prevent roof fracture in the roadway [12]. These are good for cutting off roof. So cutting effect of scheme 1 is the best.

According to scheme 1, field test was carried out, and results show that there are large differences in cutting off roof along the development direction of workface. When there is roof weighting, the cutting off roof is easy, while no weighting, there is a certain amount of roof hanging. So blasting was used as auxiliary cutting off roof technique, and good cutting effect was got, as shown in Fig. 7.

\section{Conclusions}

(1) Aiming at retaining gob-side entry for hard roof, flexible-stiff support mechanical model was built, quantitative calculation method of thickness, strength and size of flexible and stiff filling body were deduced, and filling materials of flexible and stiff support body were developed.

(2) Strain hardening characteristic of anchored gangue body was revealed, and roadside filling support technology with transversely anchored gangue body was presented for retaining gob-side entry of 
medium stable roof.

(3) Based on the slow subsidence motion characteristic of limestone roof, cutting off roof of roadside support with hydraulic props, anchor cables and auxiliary blasting was proposed, and showed good cutting effect.

\section{Acknowledgments}

This work was supported by National Natural Science Foundation of China (Nos. 51274133), Shandong Province Natural Science Fund (No. ZR2012EEZ002), Doctoral Scientific Fund Project of the Ministry of Education of China (No. 20123718110013), Graduate Innovation Fund (YC130202).

\section{Reference}

[1] Wang C W, Jiang F X, Wang P, Kong L H, "Microseismic events distribution characteristics and mechanical mechanisms of rock bursting induced by a pillar", Journal of China Coal Society, Pp 1169-1173, 2009.

[2] Wang W J, Hou C J, "Stability analysis of coal pillar and immediate bottom of extraction opening", Rock and Soil Mechanics, Pp 75-78, 2003.

[3] Wang L G, Miao X X, "Study on catastrophe characteristics of the destabilization of coal pillars", Journal of China University of Mining \& Technology, Pp 7-11, 2007.

[4] Sun H H, Zhao B L, "The theory and practice of gob-side entry retaining", China Coal Industry Publishing House, 1993.

[5] Yuan L, "Key technology for simultaneous extraction of coal/gas in low permeable high gas content coal seam cluster under pillarless gob-side entry retained with $\mathrm{Y}$ type ventilation", Journal of China Coal, Pp 9-13, 2008.
[6] Bai J B, Zhou H Q, Hou C J, Tu X Z, Yue D Z, "Development of support technology beside roadway in goaf-side entry retaining for next sublevel", Journal of China University of Mining \& Technology, Pp 183-186, 2004.

[7] Kang H P, Niu D L, Zhang Zhen, et al, "Supporting technology of gob-side entry retaining in deep coal mine", Chinese Journal of Rock Mechanics and Engineering, Pp 1977-1987, 2010.

[8] Chen Y, Bai J B, Wang X Y, Ma S Q, Xu Y, Bi T F, Yang H Q, "Support technology research and application inside roadway of gob-side entry retaining", Journal of China Coal Society, Pp 903-910, 2012.

[9] Chen Y, Bai J B, Zhu T L, Yan S, Zhao S H, Li X C, "Mechanisms of roadside support in gob-side entry retaining and its application", Rock and Soil Mechanics, Pp 1427-1432, 2012.

[10] Tang J X, Deng Y H, Tu X D, et al, "Analysis of roof separation in gob-side entry retaining combined support with bolting wire mesh", Journal of China Coal Society, Pp 1827-1831, 2010.

[11] Tan Y L, Xiang X Y, Liu C L, Zhao $\mathrm{T} B$, "Test investigation on gob-side entry retained by narrow waste-rock wall based on strain hardening model", $2013 \quad$ International Symposium on Coal Mining and Safety, Pp 10-13, 2013.

[12] Tan Y L, Zhang L J, "Gob-side entry with limestone roof retained by anchorage cable and individual prop support", Controlling Seismic Hazard and Sustainable Development of Deep Mines, Pp 143-148, 2009. 